\title{
Running the gauntlet: inhibitory effects of algal turfs on the processes of coral recruitment
}

\author{
Suzanne N. Arnold ${ }^{1, *}$, Robert S. Steneck ${ }^{1}$, Peter J. Mumby ${ }^{2}$ \\ ${ }^{1}$ Darling Marine Center, University of Maine, Walpole, Maine 04573, USA \\ ${ }^{2}$ School of Biological Sciences, University of Queensland, St Lucia Campus, Brisbane, Queensland 4072, Australia
}

\begin{abstract}
Mortality of corals is increasing due to bleaching, disease and algal overgrowth. In the Caribbean, low rates of coral recruitment contribute to the slow or undetectable rates of recovery in reef ecosystems. Although algae have long been suspected to interfere with coral recruitment, the mechanisms of that interaction remain unclear. We experimentally tested the effects of turf algal abundance on 3 sequential factors important to recruitment of corals: the biophysical delivery of planktonic coral larvae, their propensity to settle, and the availability of microhabitats where they survive. We deployed coral settlement plates inside and outside damselfish Stegastes spp. gardens and cages. Damselfish aggression reduced herbivory from fishes, and cages became fouled with turf algae, both locally increasing algal biomass surrounding the plates. This reduced flushing rates in nursery microhabitats on the plate underside, limiting larvae available for settlement. Coral spat settled preferentially on an early successional crustose coralline alga Titanoderma prototypum but also on or near other coralline algae, biofilms, and calcareous polychaete worm tubes. Post-settlement survival was highest in the fully grazed, lowest algal biomass treatment, and after 27 mo 'spat' densities were $73 \%$ higher in this treatment. The 'gauntlet' refers to the sequence of ecological processes through which corals must survive to recruit. The highest proportion of coral spat successfully running the gauntlet did so under conditions of low algal biomass resulting from increased herbivory. If coral recruitment is heavily controlled at very local scales by this gauntlet, then coral reef managers could improve a reef's recruitment potential by managing for reduced algal biomass.
\end{abstract}

KEY WORDS: Coral reef - Algal biomass - Herbivory · Parrotfish · Recruitment limitation · Caribbean $\cdot$ Demographic bottleneck $\cdot$ Bonaire

\section{INTRODUCTION}

Coral reefs worldwide suffer from large-scale and relatively sudden disturbances due to coral bleaching, disease, and other insults (e.g. Knowlton 2001, Hughes et al. 2003). Unfortunately, we know much more about what causes coral reefs to collapse than we do about what contributes to their recovery (Vermeij 2006). In the Caribbean, this was most evident in recent decades when many coral-dominated reefs phase-shifted to algal-dominated reefs (e.g. Hughes 1994, Gardner et al. 2003). Further, most Caribbean reefs have shown little or no recovery from disturbances (Connell et al. 1997, Hughes et al. 2005), and, while they decline, the debate regarding what drives coral recruitment and how to best manage for reef recovery persists.

Coral recruitment is central to the recovery of coral reefs. Logically, this involves 3 sequential steps: (1) the availability of competent larvae ready to settle to the benthos - dependent on connectivity, (2) the propensity to settle-often aided by chemical cues that induce settlement and metamorphosis, and (3) the availability of nursery habitats where post-settlement mortality of newly settled corals is low.

It is widely thought that most larvae contributing to coral recruitment originate relatively locally (Sammarco \& Andrews 1989, Hughes et al. 2000, Shanks et al. 2003). This is because corals have relatively short 
larval durations (days to weeks; Ritson-Williams et al. 2009) compared to other reef organisms such as reef fish (months) or reef lobsters (up to a year) (Steneck et al. 2009). Within this local domain, settlement occurs only after certain conditions bring competent larvae to specific depths, light (meter scale), and biogenic substrata (e.g. coralline algae) that induce metamorphosis and settlement (millimeter scale; Raimondi \& Morse 2000). Thus, for coral settlement, larval availability and the propensity to settle involve complex organismal and environmental factors that operate at multiple scales. Larval behavior at the smallest scale controls movement, metamorphosis, and settlement. Larger local-scale environmental conditions enable advection of larvae. Post-settlement survival is also strongly influenced by the local biological environment. For example, post-settlement survival for Indo-Pacific corals was enhanced at millimeter scales by particular species of coralline algae (Harrington et al. 2004). Conversely, areas of high algal biomass are known to be poor nursery habitats for settling corals (Birkeland 1977, Harriott 1983). Thus, it is possible that phase shifts to high algal biomass could reduce post-settlement survival and thereby suppress coral recruitment (Hughes \& Tanner 2000).

In the Caribbean, coral recruitment rates have declined sharply over the past few decades (Hughes \& Tanner 2000, Vermeij 2006). Hughes \& Tanner (2000) argued that loss of live coral in Jamaica reduced the number of available larvae and caused recruitment failure. However, Vermeij (2006), comparing recent coral recruitment studies with identical studies $20 \mathrm{yr}$ ago from the same location in Curacao, Netherlands Antilles, concluded that macroalgal growth had caused the reef to become hostile to settling corals, resulting in a 5-fold decline in coral recruitment there between 1979 and 1998. Thus, there is no consensus on whether the decline in coral recruitment results from a supply-side limitation in larval availability, a change in the receptivity of the reef itself, or both.

To address these questions and better manage for reef recovery, it is important to understand the causes of recruitment failure. We seek to determine what improves the chances for a coral larva to run the gauntlet of processes leading to coral recruitment. Specifically, are there demographic bottlenecks involving pre-settlement, settlement, or post-settlement processes such as the availability of larvae, their propensity to settle, or their post-settlement survivorship, respectively?

To determine the scale and rate at which recruitment operates and to develop a process-level understanding of critical steps to recruitment, we conducted experiments measuring the effects of algal abundance on recruitment in Bonaire, Netherlands Antilles. We chose Bonaire's coral reefs because the abundance of algae there is the lowest in the Caribbean (Kramer 2003) making experiments examining the effects of elevated algal abundance relatively easy to pursue. Further, by conducting the experiment on reefs with abundant corals, supply-side limitations should be relatively low (Steneck et al. 2009).

Although macroalgal abundances are low, territorial damselfish Stegastes spp. create small patches of elevated biomass in their filamentous turf 'gardens' (Brawley \& Adey 1977) by reducing herbivory in their territories (Sammarco \& Williams 1982, reviewed by Ceccarelli et al. 2001). We used the gardens from the 2 dominant territorial damselfish species on Bonaire, the three-spot $S$. planifrons and the longfin damselfish $S$. diencaeaus, to determine whether these localized differences in algal biomass affect the settlement and subsequent recruitment of corals.

We sought to determine whether potential demographically relevant limitations occur at the level of local supply of available larvae, their propensity to settle, and/or the availability of nursery habitats. We examined coral recruitment by using damselfishinduced algal turf gardens and wire cages for natural and manipulated locally elevated algal patches. We also determined the microhabitat on or near which corals settle and, with millimeter-scale spatially explicit monitoring, established the per capita survivorship and growth of newly settled corals in our experimental treatments and controls.

\section{MATERIALS AND METHODS}

Study sites. The study was conducted on the island of Bonaire, Netherlands Antilles, in the southern Caribbean $\left(12^{\circ} 15^{\prime} \mathrm{N}, 68^{\circ} 28^{\prime} \mathrm{W}\right)$. Our 6 replicate sites, all $>1 \mathrm{~km}$ apart, were along the major fringing reef track on the western (lee) side of Bonaire. Site names, from north to south, are Karpata, Barcadera, Reef Scientifico, Forest (on Klein Bonaire), Eighteenth Palm, and Windsock. The sites were chosen to characterize coral recruitment on the lee reefs of Bonaire. None of the sites were seriously damaged by Hurricane Lenny, which impacted several sites on Bonaire in November 1999.

Quantifying patterns in algae and juvenile corals. At each site, 4 replicate, $10 \times 2 \mathrm{~m}$ permanent belt transects were established parallel to the shore at $10 \mathrm{~m}$ depth. Within each belt, damselfish territories were determined through observations of both three-spot Stegastes planifrons and longfin $S$. diencaeaus damselfish over 3 min intervals, and algal community structure and density of juvenile corals were quantified. Approximately 237 quadrats of $25 \times 25 \mathrm{~cm}$ were 
placed inside and outside of damselfish territories within the belt transects on hard substrate, where algae or corals could recruit. Substrates with sediment or live invertebrates such as sponges, gorgonians, and adult coral were avoided.

In each quadrat, visual estimates of percent cover of turf algae, macroalgae, crustose coralline algae, noncoralline algal crusts (primarily peyssonnelid red algae), articulated algae (primarily Halimeda opuntia, although rare on Bonaire), and any adult coral or gorgonians and sponges were recorded. Algal turfs, or the epilithic algal community (sensu Hatcher 1983), include a multispecies group of primarily filamentous algae with canopy heights of $<10 \mathrm{~mm}$ (i.e. Ceramium spp., Polysiphonia spp., Herposiphonia spp., Centroceras spp., Taenioma spp., and Ectocarpus spp.; Steneck 1988). Macroalgae on Bonaire are rare (Kramer 2003 ) and primarily included diminutive (means \pm SE: $4.97 \pm 0.22 \mathrm{~mm}$ ) forms of both Dictyota spp. and Lobophora variegata. Crustose coralline algae refer to nongeniculate encrusting calcified red algae in the order Corallinales. The non-coralline encrusting algae are primarily peyssonnelid algae that differ from crustose coralline algae by being variably calcified with aragonite or not calcified at all and possessing tetrasporangial sori rather than conceptacles. We measured average canopy heights of foliose algae to the nearest millimeter. We calculated an algal index as a proxy for algal biomass by multiplying per group (e.g. turf) canopy height with its percent cover (Kramer 2003).

Densities of juvenile corals having recruited to the reef were determined by recording all juveniles, identified to the highest taxonomic resolution possible (i.e. genus or species level), in each quadrat. Juvenile corals included those with a maximum diameter of $40 \mathrm{~mm}$ or less (Bak \& Engel 1979, Edmunds \& Carpenter 2001), omitting those with characteristics of asexual fragmentation and those species that are characteristically small as adults (of which there are relatively few) (Richmond \& Hunter 1990). The 237 quadrats were scored, and numbers were extrapolated to square meter densities.

Settlement plates to mimic microhabitat for newly settling corals. In March 2004, 40 terra-cotta coral settlement plates of $10 \times 10 \times 1 \mathrm{~cm}$ were deployed at each site (methods of Mundy 2000; Fig. 1A). Ten plates were affixed per belt transect, half inside and half outside of damselfish territories. Thus, there were 20 plates outside damselfish territories and 20 plates inside damselfish territories per site. Multiple plates were not placed in a single damselfish territory. Holes of $0.79 \mathrm{~cm}$ diameter were drilled into dead substrate with a pneumatic drill, and stainless steel lag screws $(6.35 \mathrm{~cm}$ in length) were threaded through the plate's $0.8 \mathrm{~cm}$ center hole and screwed into $3.81 \mathrm{~cm}$ nylon wall anchors inserted into the drill holes.
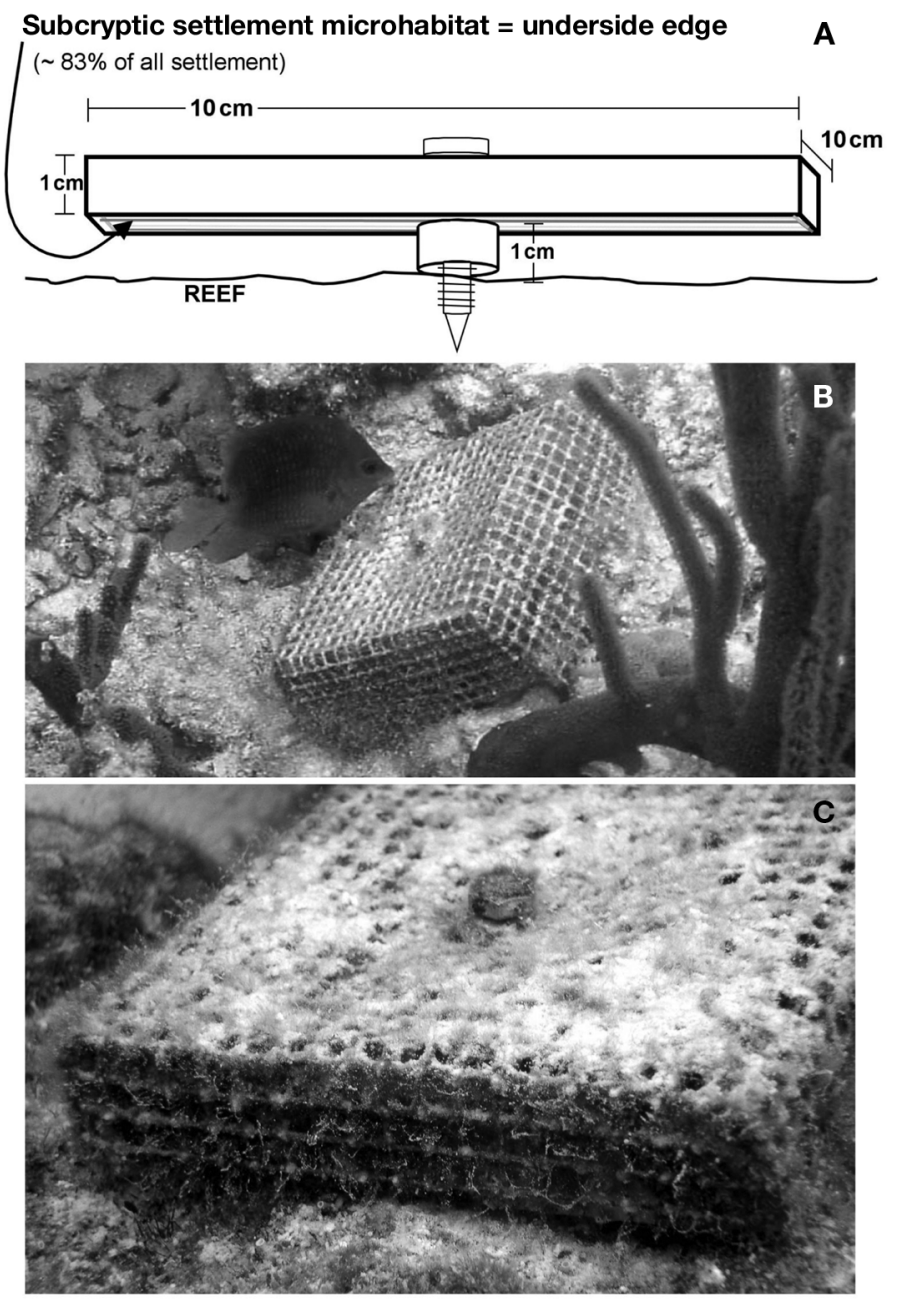

Fig. 1. Settlement plate design and algal fouled cages inside and outside of damselfish Stegastes spp. territories. (A) Sketch of $10 \times 10 \times 1 \mathrm{~cm}$ terra-cotta coral settlement plate The subcryptic settlement microhabitat, where $83 \%$ of all spat settled, is the outside $1.5 \mathrm{~cm}$ perimeter of the plate underside hidden from grazers but in close proximity to the photic zone. (B) An inside territory/caged plate-non-fully grazed treatment. (C) A cage fouled with turf algae 8 mo after cage deployment

Bare surfaces are rare on a coral reef; however, these can occur following a catastrophic disturbance, or an event damaging or killing an individual or colony. Using plates allowed not only for tracking rates of coral recruitment but also for the opportunity to track succession of colonizing organisms. Plates also homogenized topographic variance at the millimeter scale due to the simplified architecture provided by the smoothfired terra-cotta and the $1 \mathrm{~cm}$ spacer separating the plate from the reef. Since we could not standardize the topography of the substratum, we placed plates to the greatest extent possible on even, horizontal, dead coral, to reduce the irregularity in the gap between the 
reef and the plate as well as the variability of the plate orientation. At $10 \mathrm{~m}$ depth, studies have shown that spat are most frequently found on the undersides of surfaces (Carleton \& Sammarco 1987, Maida et al. 1994). Specifically in Bonaire, Raimondi \& Morse (2000) reported that, given the choice, larvae of Agaricia humilis settle on underside surfaces.

The damselfish acclimated almost immediately to this new sessile object within their territories, and the changes in territory location were negligible according to high-resolution maps created every 3 mo within the first year.

Manipulating recruitment microhabitats-damselfish territories/cages. In June 2004, 3 mo after the deployment of all the plates, we affixed 6 plates at each site with galvanized fine wire mesh $(6.35 \mathrm{~mm})$ cages to mimic the inhibitory effects of algal overgrowth on subcryptic coral recruitment microhabitats. All plate undersides were thus allowed to undergo succession free of the cages for the first 3 mo of the study. The cages, with the wire mesh nearly adhering to the plate itself, were not typical exclusion cage treatments, but rather designed to become fouled with algae (Fig. 1B,C). This treatment was deemed necessary because Bonaire has low abundances of macroalgae (Kramer 2003) compared to most Caribbean reefs that have phase-shifted to macroalgae as a result of the overfishing of grazers (Hughes 1994). Grazers, such as large denuding and scraping (sensu Steneck 1988) herbivorous fish including parrotfish (Scaridae) and surgeonfish (Acanthuridae), are effective at cropping algae on reefs and are still relatively abundant on Bonaire (Bruggemann et al. 1994, Choat et al. 2003). Thus, given our large sample size of plates, we wanted to ensure a subset would become sufficiently algal fouled without potentially confounding effects of damselfish, such as urine or mucous, on coral recruitment.

The study then consisted of settlement plates in 4 treatments. The first treatment, uncaged plates outside of damselfish territories $\left(\mathrm{n}=102 ; 17 \mathrm{site}^{-1}\right)$, was the only fully grazed treatment, expected to have the lowest algal biomass and the highest coral recruitment. The other 3 treatments, caged plates outside damselfish territories $\left(\mathrm{n}=18 ; 3\right.$ site $\left.^{-1}\right)$, uncaged plates inside damselfish territories $\left(\mathrm{n}=102 ; 17\right.$ site $\left.^{-1}\right)$, and caged plates inside damselfish territories ( $\mathrm{n}=18 ; 3$ site $^{-1}$ ) were all designed to increase algal biomass. These treatments test the hypothesis that anything that increases algal abundance, decreases coral recruitment.

Measuring larval availability. Algal biomass can reduce epibenthic water flow and thus possibly limit larval availability and settlement densities. Considering that flowmeters do not lend themselves to miniaturization to be able to measure flow in the $1 \mathrm{~cm}$ gap between the benthos and the plate underside, and that any sort of flow probe would encounter problems with the 'viewing' geometry of the experiment, to integrate flow over time, we used plaster clod cards under plates in all treatments. However, the clod cards were an appreciable fraction of the gap between the benthos and the plate in size, thereby affecting what they are designed to measure. Thus, to most realistically measure flow, we used fluorescene dye to determine flushing rates in the subcryptic microhabitat between the benthos and the underside of the plates. For this, $1 \mathrm{~mm}^{3}$ of dye was ejected from a syringe through a $1 \mathrm{~mm}$ hole drilled through the center of the plates. The duration of time from ejection to when the dye became visible at the plate edge was recorded as the treatment's flushing time.

Quantifying recruitment, substrate selectivity, and early survivorship. The plates were monitored 6 times during a 27 mo deployment period (June 2004, August 2004, November 2004, March 2005, July 2005, and June 2006). Half of the plates from each site, including all caged plates, were analyzed under the microscope each of the 6 times for newly settled corals and their subsequent survival relative to the successional community states that may positively or negatively impact recruitment. The plates censused microscopically were transported in seawater, analyzed while immersed in seawater, and returned to the reef within $6 \mathrm{~h}$. The other half of the plates remained in the water until the July 2005 monitoring period, in order to be able to detect any negative impacts of handling on the regularly sampled plates, none of which were observed. Newly settled corals are coral larvae that have recently attached themselves to the substratum and metamorphosed, defined by Morse et al. (1988) as a developmental event following attachment consisting of the differentiation and calcification of the septal ridges. For the purposes of the present paper, 'recruitment' is used in an operational sense, referring to those newly settled corals (called 'recruits' or 'spat') that have survived metamorphosis and have recognizable skeletons, dead or alive, at the time of the retrieval of the plates.

Each spat on the plate underside was identified to genus, measured, determined to be dead or alive based on the presence or absence of coral tissue and responsive polyps, and mapped for its location on the plate as well as its settlement substrate. The location of Titanoderma prototypum, an early successional coralline alga thought to be an inducer of coral settlement (Harrington et al. 2004, Ritson-Williams et al. 2010), was also mapped on the plate underside. T. prototypum is also unique in that it is relatively easy to identify early on without destructive sampling (i.e. cross section). The specific locations of spat and T. pro- 
totypum were recorded for the purposes of tracking survivorship and dispersion patterns over time. All 240 plate tops and undersides were photographed underwater to monitor for succession of fouling species. Percent coverage of encrusting biota on plate undersides (crustose coralline algae, non-coralline algal crusts, articulated algae, macroalgae, turf algae, sponges, bryozoans, and polychaete worm tubes) was determined from these digital pictures. Thus, we recorded and analyzed time series data on recruitment, growth, and mortality in reference to the succession of fouling organisms.

Analyses. Effects of damselfish territories on turf algae, juvenile corals, and spat density: Since abundance data for turf algae, juvenile corals, and spat were taken from 6 sites, for each of the 3 variables (turf algal index, juvenile coral density, and spat density), we used linear mixed effects models to examine site and treatment effects. In these tests, treatment (outside damselfish territory or inside damselfish territory) was the fixed factor and site was the random factor.

Effects of all non-fully grazed treatments on spat density and survivorship: Spat densities were generally low, and we anticipated the need to pool data in order to have sufficient power to test certain effects of the study, particularly that damselfish and cage treatments should be similar but differ from the uncaged treatment outside of a damselfish territory. In principle, we could have pooled data across the 6 sites or across the 3 cage and damselfish treatments that were expected to deliver a similar response. However, given that uneven spatial patterns of larval supply could occur among sites, we focused on the latter. To test whether pooling data from the 3 treatments was justified, we first calculated the mean recruit density per site and treatment. For each of the 6 sites, we then determined which of the 3 treatments had the highest observed spat density (note that this excluded the fourth treatment, uncaged outside damselfish territories, because this was expected to differ from the other 3 treatments). We found that each of the 3 treatments had the greatest recruit density at 2 of the 6 sites. Thus, the probability that all 3 treatments had equal likelihood of having the greatest recruit density across 6 independent sites, which would justify pooling the data from these treatments, is 0.98 , providing strong justification for pooling the treatments. This gave us 2 new treatments, 'non-fully grazed' (involving damselfishes and/or cages) and 'fully grazed'. We used these pooled data for 2 of our analyses. First, to test for a significant effect of algal fouling on spat number in 2005, we ran a mixed effects general linear model (Pinheiro \& Bates 2000), explicitly specifying site as a random effect, fouling ('non-fully grazed or 'fully grazed') as a fixed effect, and using quasi-Poisson errors. Sec- ond, we pooled the non-fully grazed treatments to examine survivorship of the August 2004 cohort because of low recruit numbers.

Multivariate analysis: Changes in the substrate composition of the undersides of the tiles were examined using non-metric multidimensional scaling ordination (MDS). Data were double square-root transformed to allow minor components of the community to influence the analysis. The relative importance of immersion time (2004 or 2005) and treatment on community composition was evaluated using 2-way ANOSIM based on the Bray-Curtis similarity coefficient with double square-root-transformed data (Clarke 1993).

\section{RESULTS}

\section{Small-scale abundance patterns in turf algae, juvenile corals, and spat density}

The calculated turf algal index surrounding the settlement plates was significantly greater (Fig. 2A; positive coefficient for 'inside damselfish territories' at 148.49, p < 0.0001, with reference level 'outside damselfish territories'), and juvenile coral density on natural substrate was significantly lower inside damselfish territories than outside damselfish territories (Fig. 2C; negative coefficient for 'inside damselfish territories' at $-0.53, \mathrm{p}<0.01$ ). Turf algae comprised most of the algal biomass since macroalgae were rare or absent at all study sites (Kramer \& Bishof 2003). Turf algal canopy heights were also significantly greater (unpaired $t$-test 2 -tailed $\mathrm{p}<0.0001$ ) on the upper surfaces of the plates inside damselfish territories (mean \pm $\mathrm{SE}: 4.14 \pm 0.16 \mathrm{~mm}$ ) versus outside damselfish territories $(2.14 \pm 0.12 \mathrm{~mm})$. Cumulative newly settled coral spat densities on the undersides of the settlement tiles were also significantly lower inside damselfish territories (Fig. 2E; rank-transformed spat density data, negative coefficient for 'inside damselfish territories' at $-13.35, \mathrm{p}<0.01$, with reference level 'outside damselfish territories'). Linear mixed effects models revealed for the 3 variables (turf algal index, juvenile coral density, and spat density) that site level differences did not mask the treatment patterns. Fig. 2B, D and $\mathrm{F}$ emphasize the variability among sites, but still show treatment effects.

Population densities of newly settled corals on plates corresponded with population densities of juvenile coral $(\leq 40 \mathrm{~mm})$ growing on natural reef substrata (Fig. 2C,E). Most spat were of the genera Agaricia $(88.8 \%)$ and Porites $(8.3 \%)$, with the remaining $2.9 \%$ unidentifiable. At this early stage, spat are only visibly discernible with a dissecting microscope to the family 

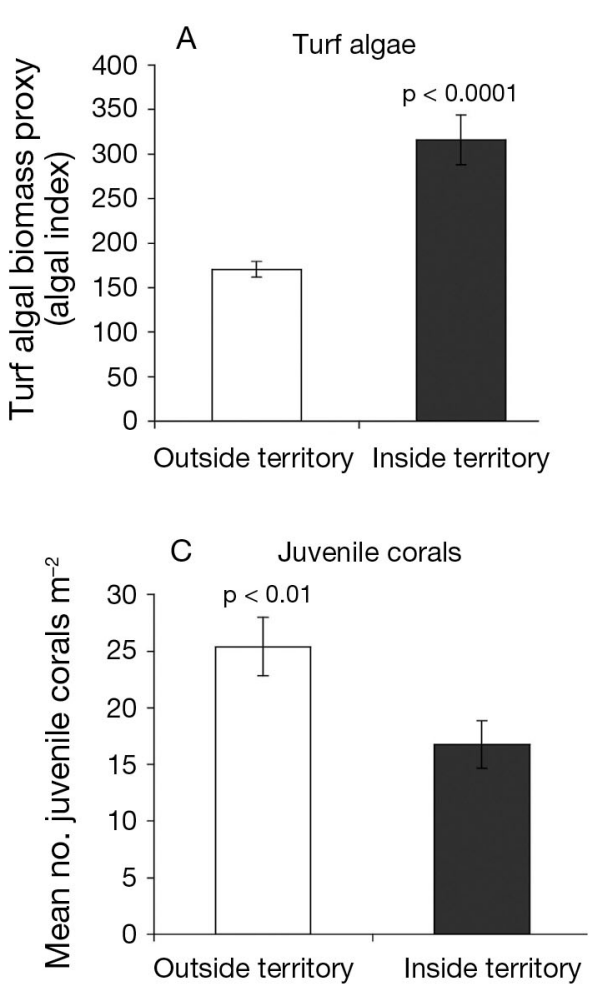

$\mathrm{E}$

Coral spat

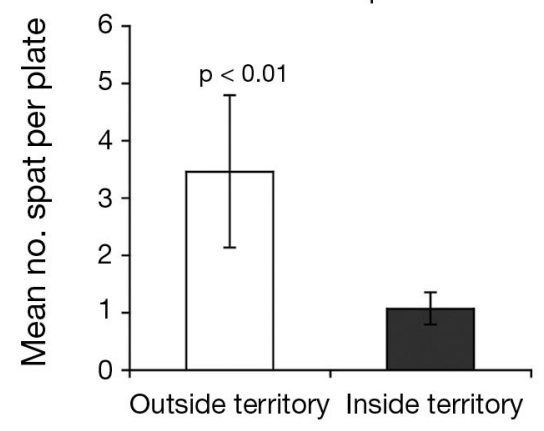

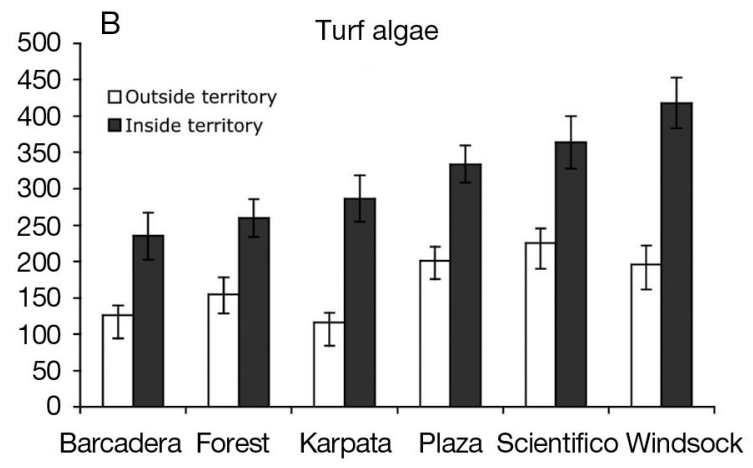
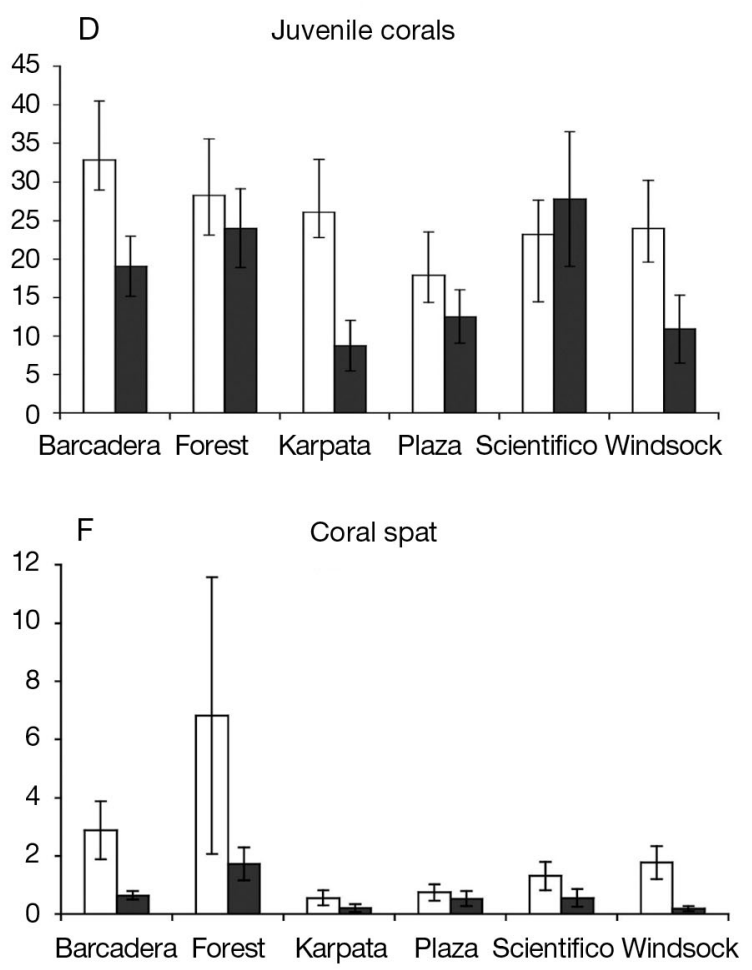

Fig. 2. Turf algal biomass proxy, juvenile coral densities, and spat densities on settlement plates outside and inside of damselfish (Stegastes planifrons, three-spot; $S$. diencaeaus, longfin) territories. Turf algal abundance surrounding the settlement plates ('algal index') is a dimensionless proxy for turf algal biomass. (A, B) Mean turf algal index (A) outside and inside damselfish territories ( $\mathrm{n}=109$ for outside territory, $\mathrm{n}=127$ for inside territories, including 74 three-spot territories and 53 longfin territories) and (B) outside and inside territories across the 6 sites. (C, D) Mean population density of juvenile corals (C) outside and inside damselfish territories and (D) outside and inside territories across the 6 sites. (E, F) Mean number of spat per terra-cotta plate (underside surface only) (E) outside and inside damselfish territories after $809 \mathrm{~d}$, pooled across sites, and (F) outside and inside territories across the 6 sites. Note that damselfish and other fish were unable to access these spat located on the underside of the plate, elevated $1 \mathrm{~cm}$ from the reef substrate. Error bars are $\pm 1 \mathrm{SE}$

or genus level (Hughes et al. 1999, Baird \& Hughes 2000). Based on juvenile abundance in the area, the species were probably Agaricia humilis, A. agaricites, and Porites astreoides, all of which are simultaneous hermaphroditic brooders, with brooding seasons ranging from year round for $A$. humilis, spring and summer for A. agaricites (Van Moorsel 1983), and January to September for P. astreoides (Szmant 1986).
To determine if there was a negative effect from removing plates for microscopy, we left a subset of the plates (60 uncaged plates outside damselfish Stegastes spp. territories and 60 uncaged plates inside damselfish territories) untouched until July 2005. Rates of recruitment were greater than or equal to those recorded on plates left untouched for the first 16 mo of the study. This indicates there were no negative effects 
due to periodic handling and observation of the plates. Of the 303 spat recorded on 240 plates, 230 , or $76 \%$, of them were found on the 120 plates that were regularly collected and examined microscopically. This high percentage included the 36 plates surrounded with wire mesh, on which there were 38 settlers. Of the 303 total spat recorded, $83 \%$ settled within $1.5 \mathrm{~cm}$ of the outer edge of the plate's underside. This 'subcryptic settlement microhabitat' (see Fig. 1A) cannot be accessed by grazers but is close to fully illuminated regions at that depth.

\section{Recruitment microhabitat manipulations- damselfish and cage effects}

Cages surrounding the coral settlement plates, like damselfish territories, were expected to increase algal biomass around the plates. The cages were deployed inside and outside damselfish territories in June 2004, and became noticeably algal-fouled by August 2004 . By July 2005, rates of recruitment were highest on uncaged plates outside of damselfish territories compared to all other treatments (Fig. 3A). The 3 non-fully grazed treatments were pooled because after calculating the mean recruit density per site per treatment these 3 treatments were found to systematically lead to the same result. Once pooled into 'fully grazed' and 'non-fully grazed', we used a generalized linear mixed effects model with quasi-Poisson errors. Here, we allowed for site effects by specifying site as a random effect. Site was found to have no significant influence and treatment effect ('fully grazed' vs. 'non-fully grazed') had a significant impact on recruit density. The coefficient for grazing was positive (1.07), and, therefore, shifting from the 'non-fully grazed' treatment to 'fully grazed' led to an increase in recruitment. The $t$-value was 3.12 , which was highly significant $(\mathrm{p}<0.01)$.

\section{Larval availability}

The increase in algal biomass surrounding the plate (i.e. not on the plate underside) reduced the rates of water flushing (Fig. 3B) in all subcryptic settlement microhabitats. The dispersal rates of dye from the gap between the plate and the reef were significantly slower among caged plates inside and outside of damselfish territories than among uncaged plates outside of damselfish territories (Tukey's honest significance multiple comparison test). Dye retention was also greater in uncaged plates inside damselfish territories than it was in uncaged plates outside of damselfish territories (Fig. 3B).
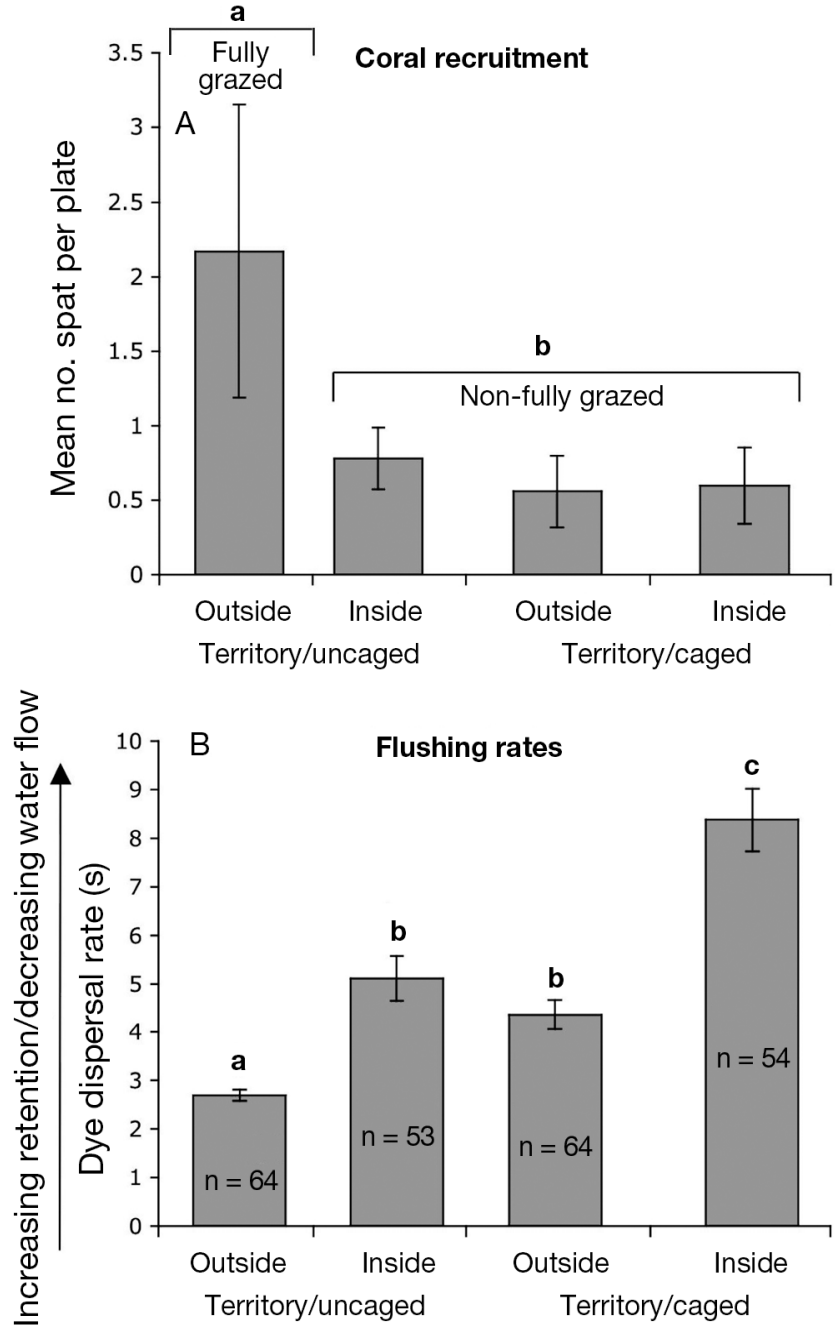

Fig. 3. Coral recruitment in the 4 treatments with corresponding flushing rates. (A) Coral spat densities on caged and uncaged plates inside and outside of damselfish Stegastes spp. territories from August 2004 through July 2005. Different letters above bars mean significant differences in mean number of recruits. (B) Dispersal rates of fluorescene dye from the plate underside for simulated treatments. Different letters above bars mean significant differences in dye dispersal rates. Error bars are $\pm 1 \mathrm{SE}$

\section{Substrate selectivity}

Coral spat preferentially recruited to specific substrates and avoided others relative to their abundance (Fig. 4A). Over half of all spat in the outer $1.5 \mathrm{~cm}$ perimeter of the plate undersides recruited to crustose coralline algae (CCA), with $33.8 \%$ on Titanoderma prototypum and $21.8 \%$ on all other species of CCA (Fig. 4A). Whereas spat recruiting in proportion to substrate abundance showed no selectivity, those recruiting to specific substrates at proportionately 
higher frequency than their abundance preferred the substrate and/or early post-settlement mortality on it was low. In either case, the substrate facilitated the process of recruitment. T. prototypum and other CCA were thus recruitment 'facilitators' based on this analysis (Fig. 4A). This was irrespective of coral species, since spat settling on $T$. prototypum were $94.6 \%$ Agaricia spp. and the overall makeup of spat on all substrates was $88.8 \%$ Agaricia spp. Conversely, turf algae and encrusting invertebrates had few or no recruits relative to their abundance and were thus recruitment 'inhibitors'. Recruitment on polychaete worm tubes could be desirable due to their micro-spatial heterogeneity, since many marine invertebrate larvae prefer to settle on irregular biogenic substrata

A

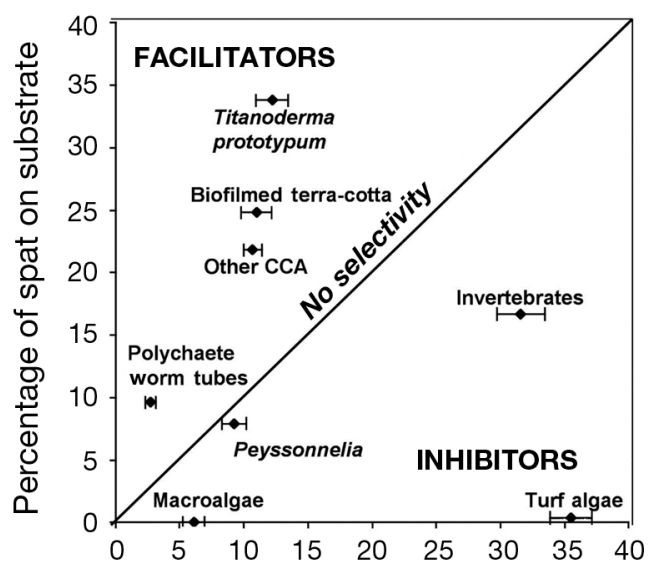

Percent cover of settlement substrate $( \pm S E)$

B

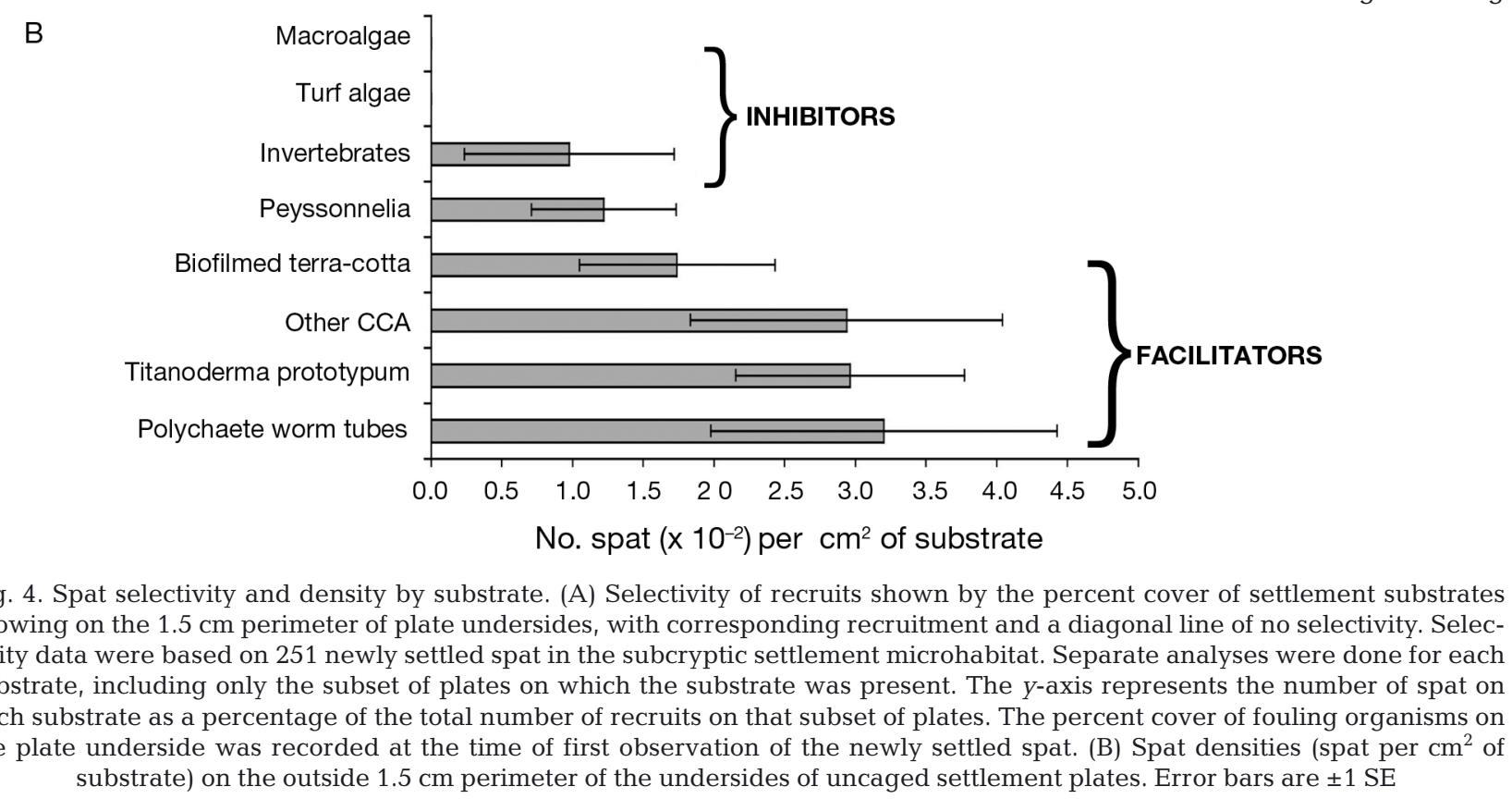

Fig. 4. Spat selectivity and density by substrate. (A) Selectivity of recruits shown by the percent cover of settlement substrates growing on the $1.5 \mathrm{~cm}$ perimeter of plate undersides, with corresponding recruitment and a diagonal line of no selectivity. Selectivity data were based on 251 newly settled spat in the subcryptic settlement microhabitat. Separate analyses were done for each substrate, including only the subset of plates on which the substrate was present. The $y$-axis represents the number of spat on each substrate as a percentage of the total number of recruits on that subset of plates. The percent cover of fouling organisms on the plate underside was recorded at the time of first observation of the newly settled spat. (B) Spat densities (spat per $\mathrm{cm}^{2}$ of substrate) on the outside $1.5 \mathrm{~cm}$ perimeter of the undersides of uncaged settlement plates. Error bars are $\pm 1 \mathrm{SE}$
(Knight-Jones 1951, Carleton \& Sammarco 1987). Once a biofilm developed on terra-cotta plates, the otherwise bare substrate also became suitable for settling corals.

Substrate-specific coral recruitment densities in subcryptic settlement habitats were greatest on polychaete worm tubes, followed by Titanoderma prototypum and other species of CCA. Spat densities were lowest or absent from invertebrate crusts, turf, and macroalgae (Fig. 4B). While polychaete tubes had high spat density, they were relatively unimportant for settling corals because they comprised such little surface area (Fig. 4A). Thus, coral spat recruited preferentially to early successional species. Coralline algal species are thin and recruit early (Adey \& Vassar 1975) to the underside of the settlement plates. We observed T. prototypum rapidly recruit and reach peak abundance $(12 \%$ cover of the entire plate underside) within 5 mo of the deployment of settlement plates. Other CCA reached peak abundance within 8 mo. In contrast, encrusting invertebrates (i.e. tunicates and sponges) and turf algae increased steadily over the $2 \mathrm{yr}$ of the study, reaching $70 \%$ cover by the end of 2 yr. As these recruitment inhibitors increased, the recruitment facilitators declined to less than half their maximum abundance due to competitive overgrowth. Thus, the 'window' for successful coral recruitment was shortlived, as succession in subcryptic microhabitats became increasingly hostile to settling corals.

To test for reductions in recruitment within this 'window' due to reduced larval availability resulting from cages and/or algal fouling, we compared the annual density of spat on coralline (facilitator) substrates in each of the 4 treatments before and after algal fouling 
of cages in 2004 and 2005, respectively. Minimal algalfouling was evident 2 mo following the June 2004 cage installation. However, cages were fully turf-fouled by November 2004, resulting in a decline in coral recruitment similar to what we had recorded inside of damselfish territories. Assuming all competent larvae encountering a facilitating substrate would settle on or near it, the difference in rates of recruitment on crustose coralline algae indicates differences in larval availability (Fig. 5A). By the summer of 2005, only fully grazed treatments (uncaged settlement plates outside of damselfish territories) had increased recruitment rates on these facilitators ( $t$-test, $\mathrm{p}=0.035)$. Recruitment on plates inside territories remained low or declined slightly, and recruitment outside of territories (initially well-grazed) that were caged in June 2004 declined significantly $(p=0.048)$.

To determine whether the treatment was influencing the community composition of the plate undersides, we compared the relative effects of treatment type and year on the substrate cover of the plates using 2-way ANOSIM. We found that year had a moderate influence $(R=0.23, p<0.001)$, whereas treatment had a very weak influence $(R=0.098, p<0.001)$ (Fig. 5B, year not shown). Similarity percentage (SIMPER) analysis (Clarke 1993) revealed that the abundance of Titanoderma prototypum was the strongest discriminating factor between the community structure of high- and low-grazing treatments (e.g. T. prototypum was ranked first for discrimination between the community structure of caged plates inside damselfish territories and uncaged plates outside territories, accounting for $18 \%$ of the mean dissimilarity in community structure between groups). Further, the fully grazed treatment was found to have a significantly greater cover of T. prototypum on the plate undersides (Fig. 5C, mixed effects linear model of arcsine-transformed cover using site, plate, and sampling time as random effects and treatment as a fixed effect gave a positive coefficient for uncaged/outside territory at $4.89, \mathrm{p}<0.0001$, with the reference level caged/outside territory).

\section{Early survivorship}

Average cohort survivorship was $18 \%$ after $365 \mathrm{~d}$, and, despite slightly different trajectories, mortality converged to a value $>90 \%$ for those cohorts by the end of 2 yr (Fig. 6A). A closer look at post-settlement survival of the August 2004 cohort (the cohort with observations closest to a 12 mo time frame) revealed that only recruits in the fully grazed treatment (uncaged plates outside of a damselfish territories) had significantly greater survivorship (Fig. 6B). Again, we
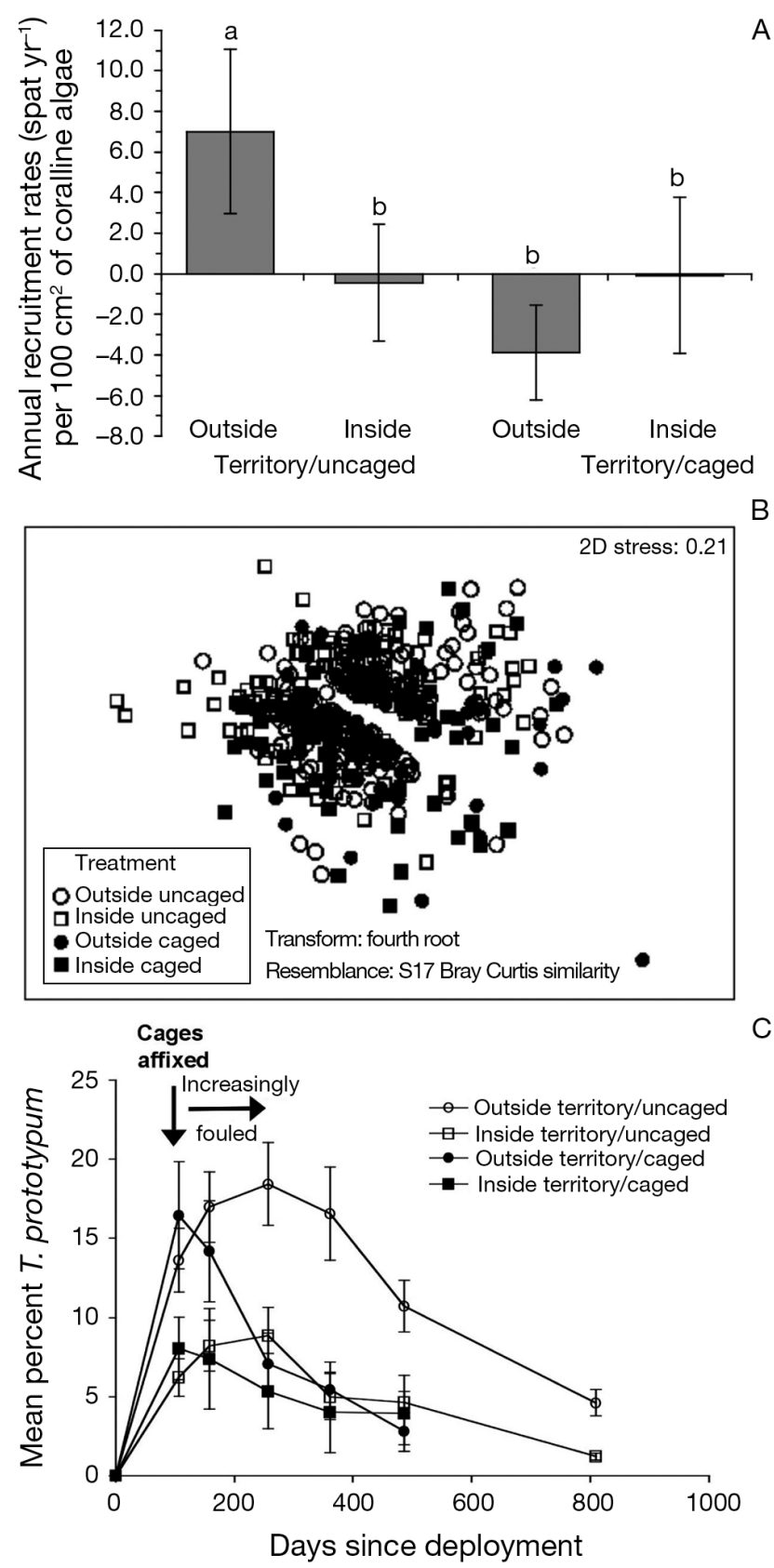

Fig. 5. Changes in rates of coral recruitment on crustose coralline algae, and a comparison of community composition resulting from elevated turf algal abundance surrounding but not on the settlement microhabitats (inside damselfish Stegastes spp. territories and inside algal fouled cages, but not on undersides of plates). (A) Deviation from initial annual recruitment (2004, prior to algal colonization of cages) for the treatment 'outside territory/uncaged' was significantly greater than for all other treatments (no overlap of $95 \% \mathrm{CI}$ ). (B) Effect of treatment type on the community composition of the plate undersides. (C) Titanoderma prototypum made up the greatest amount of difference in community composition. T. prototypum percent cover in the outside $1.5 \mathrm{~cm}$ perimeter of plate undersides. Data from caged plates were not included beyond July 2005, when the cages were no longer all fully intact. All error bars are $\pm 1 \mathrm{SE}$ 

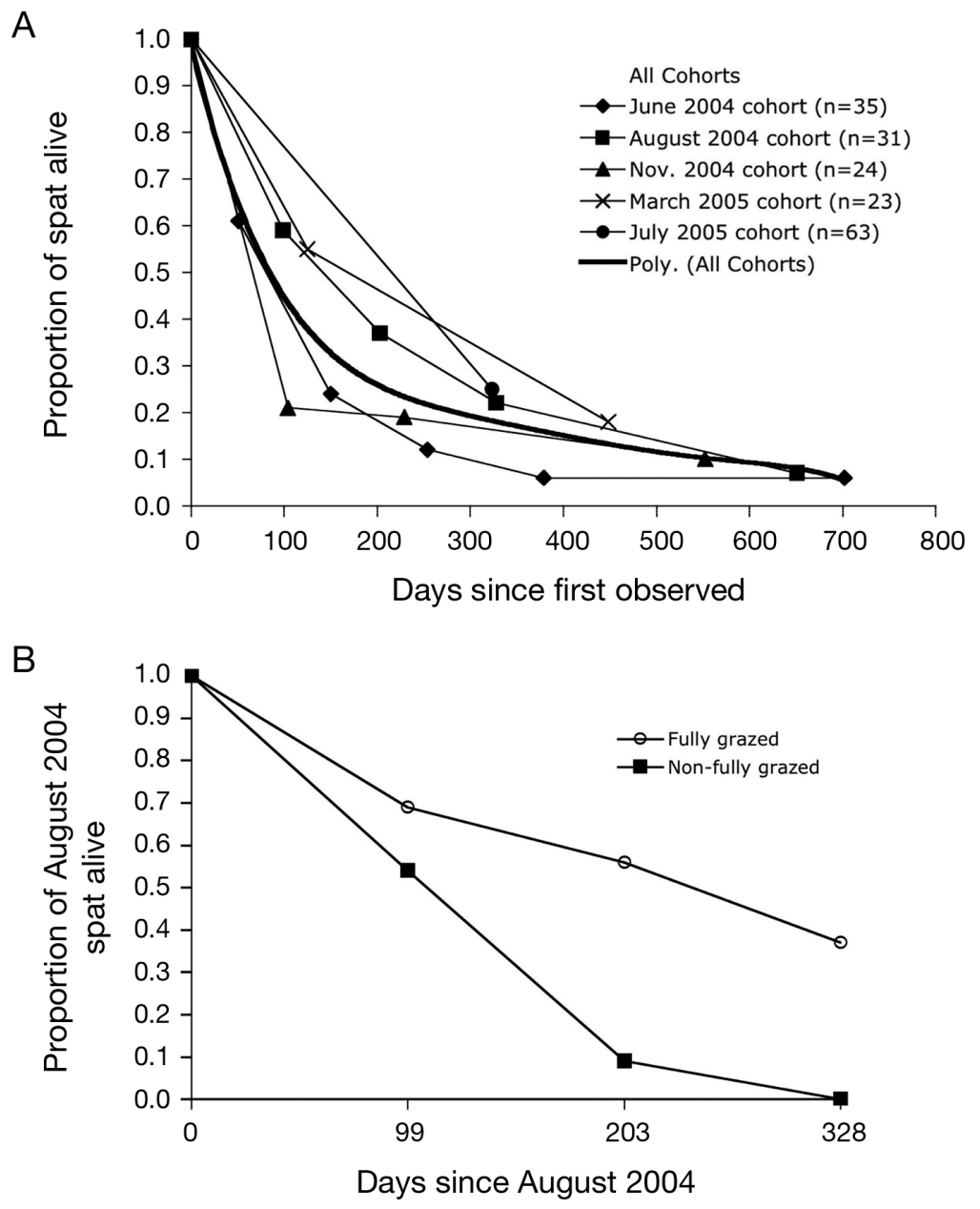

Fig. 6. Proportion of spat alive by cohort and treatment. (A) Survivorship curves for each cohort (including all treatments) from each subsequent monitoring period. A fifth-order polynomial (poly.) trendline curve fits all cohorts (in bold), highlighting an average survivorship of $18 \%$ after $365 \mathrm{~d}$ and overall mortality converging to $>90 \%$ by the end of the study. (B) Proportion of August 2004 cohort $(n=27)$ surviving during the first year of life course of the study period was $3.46 \pm 0.47$ $\mathrm{mm}$. In fully grazed conditions (uncaged plates outside of territories), $51.2 \%$ of the spat observed survived past $3.5 \mathrm{~mm}$ in diameter. Pooling the other 3 higher algal biomass treatments, only $32.3 \%$ of spat survived beyond $3.5 \mathrm{~mm}$. Considering only the surviving Agaricia spp. spat from the August 2004 cohort ( $\mathrm{n}=25$ ), those in the fully grazed treatment $(\mathrm{n}=$ 13) had greater survivorship over time, with $>50 \%$ surviving over $200 \mathrm{~d}$. Pooling the 3 other treatments $(n=12)$ resulted in only 1 spat surviving beyond $200 \mathrm{~d}$ and 0 spat surviving until the final monitoring in June 2006.

\section{DISCUSSION}

Our study suggests that elevated turf algal abundance within centimeters of possible settlement habitats decreases the recruitment potential of reefs by impeding larval access to those habitats, steering succession away from facilitator substrates, and increasing post-settlement mortality. Specifically, we suggest that 3 sequential steps - (1) the availability of competent larvae, (2) their propensity to settle, and (3) available nursery habitats (i.e. microhabitats where postsettlement mortality is low) - represent a 'gauntlet' through which coral must pass to recruit (Fig. 7). Chronic failure at any step creates a demographic bottleneck. We found that the highest proportion of surviving coral spat to successfully run pooled the non-fully grazed treatments because of low sample size (only 31 total spat were in this cohort, with 27 found alive -16 on the outside/uncaged treatment, 4 on the inside/uncaged treatment, 4 on the outside/ caged, and 3 on the inside/caged treatment). This cohort consisted of $87.0 \%$ Agaricia spp., $6.5 \%$ Porites sp., and $6.5 \%$ unidentified species. To investigate the effects of treatment on survivorship, we used the nonparametric Cox proportional hazards. The fit of the Cox model showed a significant difference in survivorship between the fully grazed treatment and the nonfully grazed treatment $(\mathrm{p}=0.016)$.

Of the spat that recruited from March 2004 through June 2006, very few survived to large size, but the highest percentage of the survivors were found under fully grazed conditions. The mean $( \pm \mathrm{SE})$ yearly growth rate of surviving Agaricia spp. spat monitored over the the gauntlet occurred under conditions of relatively low turf algal biomass.

The species composition of coral settling on our experimental plates roughly matched those naturally recruiting to the reef. For example, Agaricia spp. comprised $>88 \%$, and Porites astreoides was the second most abundant settler in our study comprising $8.3 \%$ of all spat. Similar proportions were observed among juvenile corals recruiting to natural substrates on the shallow reefs of Bonaire. Thirty years earlier in nearby Curacao, Bak \& Engel (1979) also reported densities of Agaricia spp. and P. astreoides to be 80 and $7.6 \%$, respectively.

Advection of coral larvae to subcryptic settlement microhabitats is the first step in coral settlement and ultimately recruitment to the benthos. Estimating coral larval availability is difficult because larval set- 


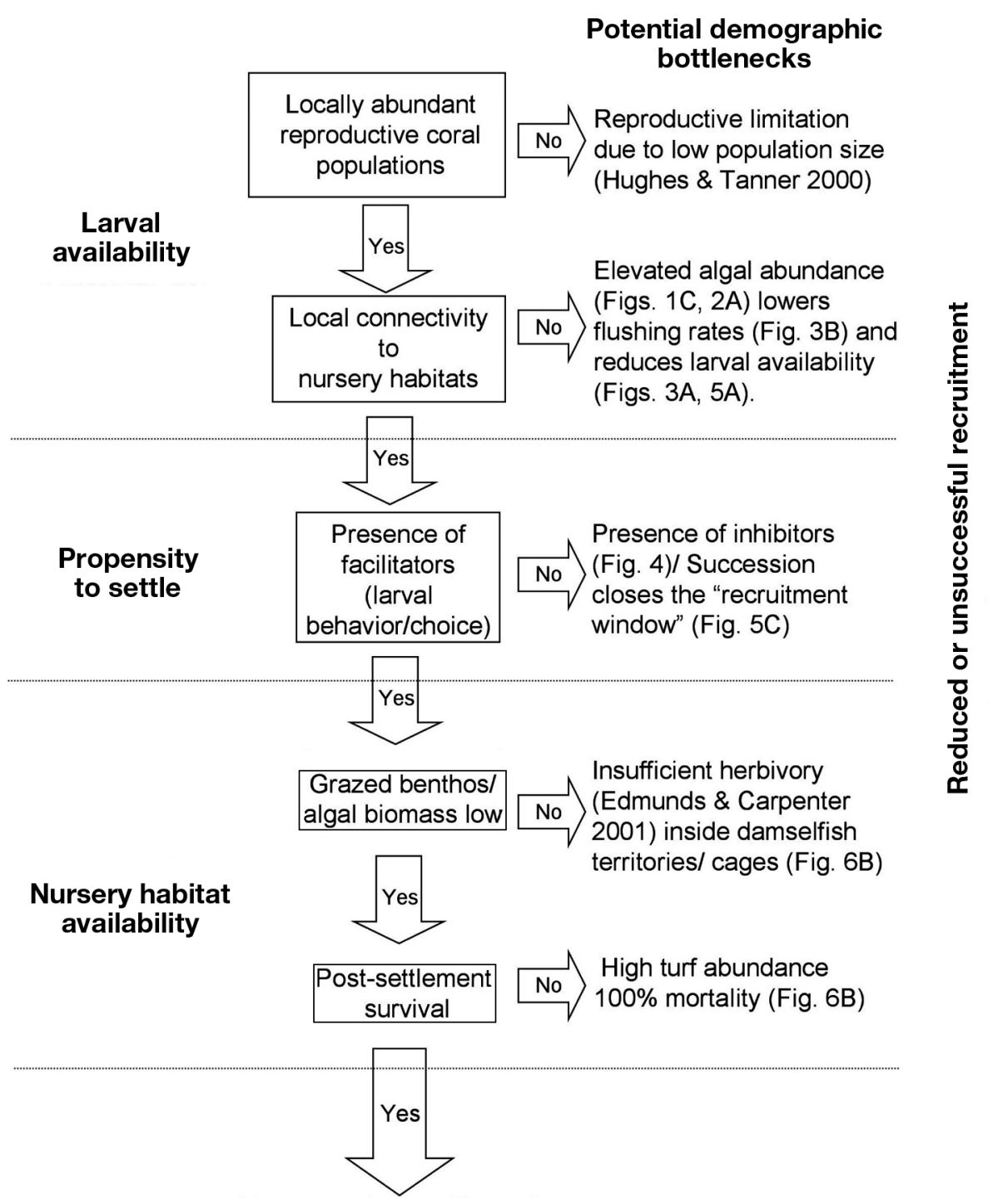

Recruitment to the benthos

Fig. 7. Conceptual model of sequential processes leading to coral recruitment to the benthos (i.e. 'the gauntlet'). Arrows to the right represent possible recruitment limitation due to demographically significant bottlenecks. Arrows down indicate a coral larva's successful progression through the sequential steps to recruitment

tlement traps do not work for corals. Thus, we used the density of coral spat on settlement-facilitating substrates (i.e. crustose coralline algae) to estimate larval availability among treatments (Fig. 5A). We reasoned that at this microhabitat scale, spat will readily settle on inducing substrata when present (Raimondi \& Morse 2000, Harrington et al. 2004), so the spat densities on these substrates should reflect the abundance of competent larvae. Over the first $158 \mathrm{~d}$ of the experiment, the recruitment density on coralline substrates did not vary among treatments. However, over the next year, as cages became increasingly fouled by turf algae, only the fully grazed uncaged plates had elevated rates of settlement (Fig. 5A). These results, together with significantly higher rates of flushing (Fig. 3B), suggest more larvae were available to settle under the fully grazed treatment. Furthermore, in terms of algal abundance, we demonstrated that the treatments only influenced the upper surfaces of the plates rather than the turf algal abundance on the undersides of the plates (Fig. 5B), ruling out the possibility that the decline in recruitment was due to anoxic conditions associated with the non-fully grazed treatments. Thus, fouled cages, damselfish Stegastes spp. gardens (Ceccarelli et al. 2001), or macroalgal-dominated reefs may reduce 
coral recruitment by starving subcryptic nursery habitats of larvae.

The behavior of coral larvae regulates their propensity to settle (Ritson-Williams et al.2009, 2010). Settlement requires that pelagic larvae undergo a sequence of behavioral changes that brings them to specific depths, seeking specific light intensities that get them to or close to subcryptic settlement habitats in relatively shallow zones of the reef (Bak \& Engel 1979, Raimondi \& Morse 2000). Once coral larvae contact the benthos, chemical cues from organisms such as encrusting coralline algae trigger their metamorphosis and settlement (Morse et al. 1988, Heyward \& Negri 1999). Preferential settlement varies among coral taxa and regions. Several coral species were induced to metamorphose and settle on a variety of encrusting and articulated calcareous algae (Heyward \& Negri 1999). Subsequent studies found several coral taxa strongly prefer to settle on the coralline alga Titanoderma prototypum (Harrington et al. 2004) on which coral spat survival is also higher. To date, the strongest species-specific coral settlement responses in the Caribbean are reported for the coralline alga Hydrolithon boergesenii, which induced settlement of the corals Agaricia humilis (Morse et al. 1988), Acropora cervicornis, and Acropora palmata (Ritson-Williams et al. 2010), as well as the CCA T. prototypum, which also induced settlement of $A$. cervicornis and A. palmata. Ritson-Williams et al. (2010) also reported that, in the field, post-settlement survival of A. palmata was facilitated by $H$. boergesenii and $T$. prototypum, whereas $A$. cervicornis survived only on T. prototypum. We found that 2 species of Caribbean coral, Porites spp. and Agaricia spp., settle preferentially on $T$. prototypum despite its low abundance (Fig. 3A). T. prototypum was found in greatest abundance on plate undersides in fully grazed treatments. However, unlike the strong facilitation of the Indo-Pacific $T$. prototypum, the Caribbean $T$. prototypum was only a slightly better settlement substrate than all other subcryptic corallines (Fig. 3). Although the Indo-Pacific and Caribbean $T$. prototypum are indistinguishable anatomically and morphologically, it is very possible they are sibling or convergent species (e.g. Steneck 1986) and may differ biochemically.

The effectiveness of 'nursery habitats' for settling corals relates to the habitat's architecture and its colonizing organisms. Shallow water corals usually settle in small crevices close to outer exposed reef habitats (Carleton \& Sammarco 1987, Maida et al. 1994, Raimondi \& Morse 2000). The proximate explanation for this pattern is light-seeking behaviors (Maida et al. 1994), but the ultimate explanation is likely that intense ecological pressures such as parrotfish grazing and overgrowth competition (Vermeij 2005) make outer exposed sur- faces in shallow reefs hostile to microscopic settling corals. Thus, there are survivorship advantages to finding subcryptic habitats from which little growth brings them to full light and subsequent rapid growth. We used terra-cotta plates to create small subcryptic microhabitats and to simplify the geometry of habitat architecture. This standardized method is used internationally (Mundy 2000). The smooth featureless settlement plate surface lacks the micro-spatial heterogeneity found on coral substrates soon after they die. Commonly, the micro-spatial heterogeneity created by the corallites of reef corals facilitates turf colonization, since their rhizoids easily attach to such spaces. Usually, grazing by excavating herbivores (Steneck 1988) and colonization by coralline algae effectively smoothes dead coral surfaces. Terra-cotta tiles effectively shorten the succession time to dominance by coralline crusts (Adey \& Vassar 1975).

Succession changes the receptivity of subcryptic habitats to coral recruitment. During the course of our experiment, the underside perimeter of plates became increasingly fouled with turf algae and heterotrophic species inimical to settlement and survival, such as invertebrate crusts. Recruitment facilitators, Titanoderma prototypum and other CCA species increased in abundance rapidly within the first half a year, but, by Day 257, their abundances peaked and then steadily declined through the duration of the study. Since thinner crusts are easily overgrown by thicker crusts (Steneck et al. 1991), the extremely thin $(40 \mu \mathrm{m}$ thick) thallus of $T$. prototypum will be readily overgrown. In an intensely competitive environment like the underside of a branched or platy coral (or settlement plate), the growth of one organism comes at the expense of another (Jackson \& Hughes 1985). The net effect in subcryptic habitats is a gradual increase of recruitment inhibitors such as turf algae and the even more detrimental invertebrate crusts. Invertebrate crusts were absent at the start of the experiment, but they steadily increased over the duration of the experiment and accounted for approximately $50 \%$ of the substrate by the last monitoring period. The regular handling of 120 of the plates during the first $16 \mathrm{mo}$ of the experiment may have caused desiccation of the sponges on the underside of the plates, explaining the higher rates of settlement on the subset of plates left untouched for the first 16 mo of the experiment. It is possible that, immediately following a disturbance that bares primary substrate, a 'recruitment window' opens as early succession-facilitating species such as $T$. prototypum (see Adey \& Vassar 1975, then called Tenarea prototypum) become established, before being overgrown by recruitment inhibitors. While this window is open, coral spat are more likely to successfully 'run the gauntlet' to recruitment. 
As with most marine organisms, post-settlement mortality is greatest during the first year when, on average, $80 \%$ of all coral spat died (Fig. 5A). In Year 2, only an additional $10 \%$ of the spat died. However, in following 1 cohort (August 2004), during our caging experiment, only coral spat from fully grazed treatments survived the first year (Fig. 5B). In fact, over the entire study, the greatest proportion of agaricid spat to reach the largest size classes were in the fully grazed treatments.

Spat survival is not merely a function of the attributes of the settlement substrate, but of their ability to resist overgrowth by algae and encrusting invertebrates (Richmond 1997). As recruits grow, their mortality rates usually decline and they are less likely to be overgrown by competitors (Hughes \& Jackson 1985). However, the slow growth rates of newly settled corals keep them at risk of losing this battle. A critical but largely unstudied dynamic may be how, as surrounding algal biomass increases, subcryptic habitat colonizers shift from slow growing, recruitment facilitating autotrophs (e.g. Titanoderma prototypum) to faster growing, recruitment inhibiting heterotrophs (e.g. encrusting invertebrates). During the timescale of the present study, the community structure of the plate undersides actually varied little between treatments (Fig. 5B), with the percent cover of the facilitator $T$. prototypum (Fig. 5C) making up the majority of the difference. It is possible that a macroalgal-dominated reef, more typical of other Caribbean reefs, would have led to a more rapid decline of facilitator species and rise of heterotrophs, thereby decreasing settlement and survivorship.

As the decline of Caribbean reefs continues (Gardner et al. 2003), so too does the dichotomy in thinking as to why they fail to recover. Is the lack of recovery due to the loss of reproductive populations and the resulting decreased larval pool (Hughes \& Tanner 2000), or is it more the result of local declines in the recruitment potential of the benthos (Hughes \& Tanner 2000, Bellwood et al. 2004)?

Our study suggests that local herbivory-induced low algal biomass increases the receptivity of the reef and may be critical for recruiting corals and the recovery of the reef ecosystem. In Jamaica live coral cover was remarkably low following the mass mortality of the herbivorous sea urchin Diadema antillarum (e.g. Hughes 1994); as this urchin increased in abundance, so too did juvenile corals (Edmunds \& Carpenter 2001) and eventually adult corals (Idjadi et al. 2006).

We suggest that herbivory, or whatever controls algal abundance, has a strong effect on coral recruitment. Thus, that which effects herbivory, even at local scales measured in centimeters, explains a considerable portion of the variance associated with coral recruitment. The management implications of this are obvious. First, managing for low algal biomass is both a laudable and attainable goal. Herbivory from abundant, deep-grazing sea urchins and/or parrotfishes may be necessary for reef recovery due to the positive indirect effects they have on the recruitment potential of reefs. Second, if large predators control damselfish abundance (Hixon \& Beets 1993) and damselfish reduce local herbivory (Ceccarelli et al. 2001), then predator abundance may also indirectly control herbivory and thus the recruitment potential of the reef.

Finally, we suggest that a sequence of local processes control coral recruitment at small spatial scales. This, together with studies finding limited larval dispersal among corals (Sammarco \& Andrews 1988, Hughes et al. 1999), suggests we should not rely on 'recruitment effects' or large-scale, supply-side spillover from healthier upstream reefs, but focus management efforts locally (Steneck 2006). While massive coral die-offs often result from pulse events operating at landscape scales, recovery is usually highly variable and spatially limited (Idjadi et al. 2006, Golbuu et al. 2007). Thus, the recovery of coral reef ecosystems depends on the few survivors that successfully run the gauntlet to recruitment through the sequence of local multiscale processes.

Acknowledgements. This research was only possible due to the support received on Bonaire, particularly by the Bonaire National Marine Park (STINAPA). Specifically, support was received from Elsmarie Beukenboom, Ramon de Leon, Fernando Simal, Din Domacasse, Kalli de Mayer and all the STINAPA rangers, staff, and volunteers who contributed their time and helped with logistics. Jeanne Brown, Curt Brown, Susan Porter, and Thew Suskiewicz helped us in the field. Early drafts of the manuscript were critiqued by Susan Brawley and Dan Brumbaugh. Funding was from the Pew Fellows for Marine Conservation, the Kendall Foundation, the Connectivity Working Group of the Global Environmental Fund Research and Capacity Building Project, National Fish and Wildlife Foundation, NERC, and STINAPA Bonaire. To all we are grateful.

\section{LITERATURE CITED}

Adey WH, Vassar JM (1975) Colonization, succession and growth rates of tropical crustose coralline algae (Rhodophyta, Cryptonemiales). Phycologia 14:55-69

Baird AH, Hughes TP (2000) Competitive dominance by tabular corals: an experimental analysis of recruitment and survival of understory assemblages. J Exp Mar Biol Ecol 251:117-132

Bak RPM, Engel MS (1979) Distribution, abundance and survival of juvenile hermatypic corals (Scleractinia) and the importance of life history strategies in the parent coral community. Mar Biol 54:341-352

$>$ Bellwood DR, Hughes TP, Folke C, Nystrom M (2004) Confronting the coral reef crisis. Nature 429:827-833

Birkeland C (1977) The importance of rate of biomass accumulation in early successional stages of benthic communi- 
ties to the survival of coral recruits. In: Taylor DL (ed) Proc 3rd int coral reef symp. Miami School of Marine and Atmospheric Sciences, University of Miami, Miami, FL, p 15-22

Brawley SH, Adey WH (1977) Territorial behavior of threespot damselfish (Eupomacentrus planifrons) increases reef algal biomass and productivity. Environ Biol Fishes 2: 45-51

Bruggemann JH, Kuyper MWM, Breeman AM (1994) Comparative analysis of foraging and habitat use by the sympatric Caribbean parrotfish Scarus vetula and Sparisoma viride (Scaridae). Mar Ecol Prog Ser 112:51-66

Carleton JH, Sammarco PW (1987) Effects of substratum irregularity on success of coral settlement: quantification by comparative geomorphological techniques. Bull Mar Sci 40:85-98

Ceccarelli DM, Jones GP, McCook LJ (2001) Territorial damselfishes as determinants of the structure of benthic communities on coral reefs. Oceanogr Mar Biol Annu Rev 39: 355-389

Choat JH, Robertson DR, Ackerman JL, Posada JM (2003) An age-based demographic analysis of the Caribbean stoplight parrotfish Sparisoma viride. Mar Ecol Prog Ser 246: 265-277

> Clarke KR (1993) Non-parametric multivariate analyses of changes in community structure. Aust J Ecol 18:117-143

Connell JH, Hughes TP, Wallace CC (1997) A 30-year study of coral abundance, recruitment, and disturbance at several scales in space and time. Ecol Monogr 67:461-488

Edmunds PJ, Carpenter RC (2001) Recovery of Diadema antillarum reduces macroalgal cover and increases abundance of juvenile corals on a Caribbean reef. Proc Natl Acad Sci USA 98:5067-5071

Gardner TA, Cote IM, Gill JA, Grant A, Watkinson AR (2003) Long-term region-wide declines in Caribbean corals. Science 301:958-960

- Golbuu Y, Victor S, Penland L, Idip D Jr and others (2007) Palau's coral reefs show differential habitat recovery following the 1998 bleaching event. Coral Reefs 26: 319-332

> Harrington L, Fabricius K, De'ath G, Negri A (2004) Recognition and selection of settlement substrata determine postsettlement survival in corals. Ecology 85:3428-3437

Harriott VJ (1983) Reproductive seasonality, settlement, and post-settlement mortality of Pocillopora damicornis (Linnaeus), at Lizard Island, Great Barrier Reef. Coral Reefs 2: 151-157

Hatcher BG (1983) Grazing in coral reef ecosystems. In: Barnes DJ (ed) Perspectives on coral reefs. Australian Institute of Marine Science, Townsville, p 164-179

Heyward AJ, Negri AP (1999) Natural inducers for coral larval metamorphosis. Coral Reefs 18:273-279

- Hixon MA, Beets JP (1993) Predation, prey refuges, and the structure of coral-reef fish assemblages. Ecol Monogr 63: $77-101$

Hughes TP (1994) Catastrophes, phase shifts, and large-scale degradation of a Caribbean coral reef. Science 265: $1547-1551$

Hughes TP, Jackson JBC (1985) Population dynamics and life histories of foliaceous corals. Ecol Monogr 55:141-166

Hughes TP, Tanner JE (2000) Recruitment failure, life histories, and long-term decline of Caribbean corals. Ecology 81:2250-2263

Hughes TP, Baird AH, Dinsdale EA, Moltschaniwsky JNA, Pratchett MS, Tanner JE, Willis BL (1999) Patterns of recruitment and abundance of corals along the Great Barrier Reef. Nature 397:59-63
Hughes TP, Baird AH, Dinsdale EA, Moltschaniwsky JNA, Pratchett MS, Tanner JE, Willis BL (2000) Supply-side ecology works both ways: the link between benthic adults, fecundity, and larval recruits. Ecology 81:2241-2249

Hughes TP, Baird AH, Bellwood DR, Card M and others (2003) Climate change, human impacts, and the resilience of coral reefs. Science 301:929-933

Hughes TP, Bellwood DR, Folke C, Steneck RS, Wilson J (2005) New paradigms for supporting the resilience of marine ecosystems. Trends Ecol Evol 20:380-386

Idjadi JA, Lee SC, Bruno JF, Precht WF, Allen-Requa L, Edmunds PJ (2006) Rapid phase-shift reversal on a Jamaican coral reef. Coral Reefs 25:209-211

Jackson JBC, Hughes TP (1985) Adaptive strategies of coralreef invertebrates. Am Sci 73:265-274

Knight-Jones EW (1951) Gregariousness and some other aspects of the settling behaviour of Spirobis. J Mar Biol Assoc UK 30:210-222

Knowlton N (2001) The future of coral reefs. Proc Natl Acad Sci USA 98:5419-5425

Kramer PA (2003) Synthesis of coral reef health indicators for the western Atlantic: results of the AGRRA program (1997-2000). In: Lang JC (ed) Status of coral reefs in the western Atlantic: results of initial surveys, Atlantic and Gulf Rapid Reef Assessment (AGRRA) Program. Atoll Res Bull 496:1-55

Kramer PA, Bishof BG (2003) Assessment tables for Aboaco, Bahamas (fish), Lighthouse Atoll, Belize (corals, algae, fishes), and Bonaire, Netherlands Antilles (corals, algae, fishes). Atoll Res Bull 496:590-597

Maida MJ, Coll JC, Sammarco PW (1994) Shedding new light on scleractinian coral recruitment. J Exp Mar Biol Ecol 180:189-202

Morse ED, Hooker N, Morse ANC, Jensen A (1988) Control of larval metamorphosis and recruitment in sympatric agariciid corals. J Exp Mar Biol Ecol 116:193-217

Mundy CN (2000) An appraisal of methods used in coral recruitment studies. Coral Reefs 19:124-131

Pinheiro JC, Bates DM (2000) Mixed-effects models in S and S-plus. Springer-Verlag, New York, NY

Raimondi PT, Morse NC (2000) The consequences of complex larval behaviour in a coral. Ecology 81:3193-3211

Richmond RH (1997) Reproduction and recruitment in corals: critical links in the persistence of reefs. In: Birkeland C (ed) Life and death of coral reefs. Chapman \& Hall, New York, NY, p 175-197

> Richmond RH, Hunter CL (1990) Reproduction and recruitment of corals: comparisons among the Caribbean, the tropical Pacific, and the Red Sea. Mar Ecol Prog Ser 60: 185-203

Ritson-Williams R, Arnold SN, Fogarty ND, Steneck RS, Vermeij MJA, Paul VJ (2009) New perspectives on ecological mechanisms affecting coral recruitment on reefs. Smithson Contrib Mar Sci 38:437-457

Ritson-Williams R, Paul VJ, Arnold SN, Steneck RS (2010) Larval settlement preferences and post-settlement survival of the threatened Caribbean corals Acropora palmata and A. cervicornis. Coral Reefs 29:71-81

Sammarco PW, Andrews JC (1988) Localized dispersal and recruitment in Great Barrier Reef corals: the helix experiment. Science 239:1422-1424

Sammarco PW, Andrews JC (1989) The helix experiment: differential localized dispersal and recruitment patterns in Great Barrier Reef corals. Limnol Oceanogr 34:896-912

Sammarco PW, Williams AH (1982) Damselfish territoriality: influence on Diadema distribution and implications for coral community structure. Mar Ecol Prog Ser 8:53-59 
Shanks AL, Grantham BA, Carr MH (2003) Propagule dispersal distance and the size and spacing of marine reserves. Ecol Appl 13:159-169

Steneck RS (1986) The ecology of coralline algal crusts: convergent patterns and adaptative strategies. Annu Rev Ecol Syst 17:273-303

Steneck RS (1988) Herbivory on coral reefs: a synthesis. In: Choat JH, et al. (eds) Proc 6th int coral reef symp. Symposium Executive Committee, Townsville, p 37-49

Steneck RS (2006) Staying connected in a turbulent world. Science 311:480-481

Steneck RS, Hacker SD, Dethier MN (1991) Mechanisms of competitive dominance between crustose coralline algae: an herbivore-mediated competitive reversal. Ecology 72: 938-950

Steneck RS, Paris CB, Arnold SN, Ablan-Lagman MC and

Editorial responsibility: Charles Birkeland,

Honolulu, Hawaii, USA others (2009) Thinking and managing outside the box: coalescing connectivity networks to build region-wide resilience in coral reef ecosystems. Coral Reefs 28: $367-378$

Szmant AM (1986) Reproductive ecology of Caribbean reef corals. Coral Reefs 5:43-53

Van Moorsel GWNM (1983) Reproductive strategies in two closely related stony corals (Agaricia, Scleratinia). Mar Ecol Prog Ser 13:273-283

Vermeij MJA (2005) Substrate composition and adult distribution determine recruitment patterns in a Caribbean brooding coral. Mar Ecol Prog Ser 295:123-133

> Vermeij MJA (2006) Early life-history dynamics of Caribbean coral species on artificial substratum: the importance of competition, growth and variations in life history strategy. Coral Reefs 25:59-71

Submitted: March 17, 2010; Accepted: July 4, 2010 Proofs received from author(s): August 27, 2010 